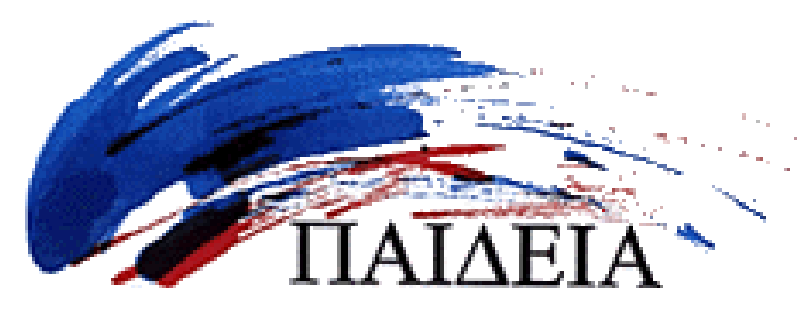

Philosophy of Values

\title{
Preference-utilitarianism and Past Preferences
}

\author{
Toni Rønnow-Rasmussen \\ Lund University \\ Toni.Ronnow-Rasmussen@fil.lu.se
}

\begin{abstract}
A well-known problem for preference-utilitarianism is to what extent it should exclude from consideration certain preferences. In this paper I focus on past preferences. I outline three general and some particular positions that a preferenceutilitarian reasonably would want to take with regard to past preferences and why I think that endorsing each of these positions create new problems for the preference-utilitarian. At the end I sketch on a possible solution to the axiological problems here presented. However, although the pluralistic approach that I outline shares with preferenceutilitarianism the idea that what is valuable is the satisfaction of preferences, it is not a viable option for a utilitarian. My conclusion is therefore that preference-utilitarianism faces a serious axilogical problem.
\end{abstract}

Preference-utilitarianism is a so-called consequentialist theory. As such it decides whether a certain act should be done or not by considering whether the consequences of the act will maximise (expected) preference-fulfilment (or at least be as good as the consequences of any alternative act with regard to expected preference-fulfilment). Moreover, preference-utilitarianism differs from other versions of utilitarianism by its axiological stand - what recently has been called preferentialism (Rabinowicz and Österberg 1996) (1) - which claims something to the following effect: Intrinsic value is based or determined by (intrinsic) preferences.

A well-known problem for preference-utilitarianism is to what extent it should exclude from consideration certain preferences (such as antisocial preferences and so-called irrational ones). The kind of preferences that I will focus on here with regard to this question has received less attention than other kinds. Thus, the problem that I will address is to what extent preference-utilitarians should allow a certain subset of past preferences into the weighing. Or to be more specific, I want to consider just what a utilitarian should do with those past preferences the object of which is located in the present (or in the 
future). Once we keep in mind that most preferences of the past are not of this kind, and since I will not be concerned with any of the other kinds of preferences of the past, I will henceforth refer to this kind of preferences as simply 'past preferences'.

The axiological issue that past preferences raise not just for preference-utilitarians but for everyone who thinks preference-fulfilment constitutes a benefit, is of such a dignity that the matter should not be put aside. (2) By outlining some plausible alternatives to how a preference-utilitarian can deal with these preferences (and why I think that these approaches are not convincing), I make a first attempt in this paper to remedy this situation. However, a caveat is in place: my results are meagre; I see with one exception no obvious way out of the axiological problems that I address here. And the exception I sketch on at the end squares badly with preference utilitarianism.

\section{l.}

In order to find a clear way of speaking about these past preferences it will prove useful to time-index a person's preferences (in much the same way as R. M. Hare has done). (3) My first step will therefore be to (re)introduce this terminology and to consider some complementary ways of describing preferences.

When it comes to the preferences of a person in the present (a so-called present or actual person in contrast to a past, future or hypothetical person) there will be various kinds. Thus, not all will be socalled now-for-now preferences - that is, preferences that concern the moment (or period of time) when the person has the preference (cf. Hare 1981). Typically a person will also have preferences regarding situations other than the one that is simultaneous with having the preference. For instance, I may at this moment prefer that the doctor with whom I have an appointment tomorrow will tell me then the truth about my state of health. Or I may prefer now that yesterday I had not spent all my money on the lottery.

A person in the present may in other words have so-called now-for-future preferences and now-for-past preferences (Here I deviate slightly from Hare's denomination). It is with the former group that I will be concerned. Or, more accurately, it is preferences of this kind that belong to the past that I will discuss. Future preferences concerned with the present raise similar problems but will not be dealt with here.

Having considered some different ways of describing a person's present preferences, we should next distinguish them from a person's non-actual preferences. (4) Such non-actual preferences are future, past and hypothetical preferences. For a preference-utilitarian, hypothetical preferences deserve attention notably because it is often said that rational preferences are those we would have if some ideal circumstance were the case. However, since I will not be addressing questions concerning the rationality of intrinsic preferences, I will put hypothetical preferences aside.

Let us call those now-for-future preferences that with the passing of time have become a part of the past "past-for-now preferences". To be accurate it is possible to detect more kinds of such past preferences. Thus, the past preference does not have to be directed towards the present. It's object can be located to the future as well as to some other time that by the passing of time now belongs to the past. Henceforth, 
I will, however, be focusing on the past-for-now preferences. The "now", by the way, does not have to be understood in the narrow sense of referring to a "point in time" - nothing hinges here on whether we allow it to be about a period of time.

Given the above distinctions we can reformulate our initial question in the following way: should the preference-utilitarian treat past-for-now preferences on a par with present (and future) preferences?

To treat a preference $p$ on a par with another preference $q$ is, I will say, to let only the strength of the preferences determine which of them should be fulfilled. A preference weighs, in other words, in the utilitarian calculation (or weighing process) purely in proportion to its strength. So if preference $p$ is stronger than $q$, and we cannot fulfil both, it is $p$ we should fulfil. (5)

There are three general positions that we can take towards past preferences; we can say that we should (1) never, (2) always or (3) sometimes treat past-for-now preferences on a par with present preferences. I will start examining these positions in section 3. In the meantime it is a good idea to draw attention to something which Rabinowicz and Österberg (1996) have pointed out, namely that there are two clearly distinguishable versions of preferentialism

\section{2.}

Let us call the first alternative the Fulfilment version of preferentialism. It makes the following claim (C1): intrinsic value is assigned to the circumstance that our intrinsic preferences are fulfilled.

Normally the Fulfilment version of preferentialism is regarded as laying a wide step away from another kind of axiology, what has been called Value-objectivism. However, Rabinowicz and Österberg discuss a version that is inspired by value-objectivism but which encompasses the intuition that value has its source in preferences. Let us call this version "Object-preferentialism". In spite of its proposal that what has intrinsic value has preferences as its source, it is distinguished from the Fulfilment version (C1) in endorsing the following thesis (C2): intrinsic value is assigned to the object(s) of our (intrinsic) preferences.

What unites Object-preferentialist is their claim that the constitutive ground for the intrinsic value of an object is preferences. However, the intrinsic value of this object supervenes not on the preferences but on the intrinsic (non-relational) properties of the object. Object-preferentialist are convinced (as was Moore) that the very notion "intrinsic value" is not with regard to any conscious state of humans (or, for that matter, sentient beings) a relativized notion - at least not in any other sense than what has intrinsic value has a preference as its source. Notwithstanding, admitting this is not admitting, Objectpreferentialists maintain, that if our preferences changed what is of intrinsic value would change too.

Object-preferentialists face several problems, qua utilitarians. Some appear so great that doubt has been expressed as to whether such a view can constitute the axiological part of utilitarianism. (6) My suspicion is that it cannot. For one thing, it must deal with the problem of how value can be aggregated when it is not the same commodity. No utilitarian theory can ignore this problem. But Object- 
preferentialists have a further, equally serious task to take on, namely, the difficult business of showing that even if it is preferences that "point out" the values, what is of intrinsic value will not vary when our preferences change. At the moment I do not see how this can be done.

In this connection it is also important to notice that we can get different versions of $(\mathrm{C} 1)$ and $(\mathrm{C} 2)$ depending on whether or not we are ready to restrict the kind of preferences on which the intrinsic value is based. A possible (but as we shall see, not very plausible) version would be one that maintained that it is only preferences that has experiences as object that determine intrinsic value. In section 3 I consider such a claim. The reason is that it prima facie seems to support the idea that we should never treat past preferences on a par with actual ones. But from section 4 onwards I will focus on an unrestricted version of preferentialism. Moreover, in what follows, I will confine my attention to the fulfilment version of preferentialism. The axiological problems that past preferences create will be much the same whether or not we regard preferentialism as being a fulfilment theory or as an object theory.

\section{3.}

Let us begin with (1). Why would a preference-utilitarian (or for that matter anyone) want to endorse the idea that past preferences should never be treated on a par with present ones? Perhaps the reason is as simple as what is expressed by, what we can refer to as the Impossibility version, (I1, for short): Pastfor-now preferences cannot be fulfilled, and should therefore not be given any value at all.

The reason expressed in (I1) is one that turns up now and then in discussions concerning preferences of the past. But despite this the reply is not very plausible. It challenges a common view what should count as preference-fulfilment, viz., that the fulfilment of a desire is, as Brandt convincingly says, "for the desired event to occur". (7) Since the object (8) of past-for-now preferences occurs in the present, such preferences can in principle, according to this view, be fulfilled in the present in contrast to some other kinds of preferences of the past. This does not imply that all past-for-now preferences can be satisfied (Henceforth I will use 'satisfied' and 'fulfilled' as synonyms). It only means that the time factor (i.e. that it is a past preference) does not prevent this kind of past preferences from being satisfiable.

I am not sure what advocates of (I1) would endorse as an alternative to the above view on preferencefulfilment. Perhaps a suggestion might be to regard preference-fulfilment as a relation between the preference and its object. An argument for the impossibility-thesis could then set out from the idea that a relation requires the existens of both relata. Thus, if the past does not exist there cannot be any relation in the present between the past-for-now preference and its object. On such a view it would, in other words, not be enough that the object of the desire obtains (at the time, we can add, it is intended to obtain).

But whether or not we agree that the past exist, the above suggestion is not convincing; it would in effect mean that there would be no real point in having such kind of preferences. However, judging from the literature there is ample evidence that people say they have desires such as: I want to give money to, say, Oxfam, and I want to do so later on, even if I for selfish reasons later on would not want 
to do so. Another case in point would be so-called deathbed wishes. Surely we can understand what it would be like to satisfy preferences such as these even if it was the case that the preferrer at the later point no longer existed or did not any longer desire what he or she originally desired. I see no reason why we cannot say that a desire that I have now for some $p$ to obtain at a later time has been satisfied at that later time if $p$ obtains at that later time.

The first reason, (I1), why we should never treat past preferences on a par with present ones is, in other words, not convincing. (9) However, it is possible to specify (1) in at least two interesting ways that each requires an axiological foundation. Thus, the first specification, which we can refer to as the Weight version, (W1), states that past-for-now preferences should never be treated on a par with present preferences because they should (at least sometimes) be treated as having either more or less value than what strength alone requires of us to give to them. But since a similar position will show up when we discuss (3) I will leave this option for the moment.

The second way of understanding (1) can be called the Exclusion version, (E1); it does not deny that the past desires under discussion can be satisfied. Rather, what it suggests is that although past-for-now preferences can be satisfied (in Brandt's sense), we should just not place any value on the fulfilment of such preferences. Thus, in contrast to (W1) this position does not acknowledge the possibility of "downgrading" of preferences; if a preferences is to count it will always be the strength of the preference that determines its value.

The (E1) alternative is clearly the most interesting one, implying as it does, that there is something about the fulfilment of past preferences that makes this kind of fulfilment different (in terms of its value) from other kinds of preference-fulfilment. So which axiology would best support a position such as $(\mathbf{E} 1)$ ?

By specifying in a certain way what we mean by preference-fulfilment (and recall that we are confining our attention to the fullfilment version preferentialism) - we can then reach an axiological position that has the desired consequence of supporting (E1):

$A X 1$ : intrinsic value is assigned to the pleasure that accompanies the experienced fulfilment of intrinsic preferences (cf. Lemos 1994, pp. 84).

Obviously, $A X 1$ would support the idea that we should never treat past preferences on a par with, or as having either more or less value than present ones. (10)

The expression "pleasure" is notoriously tricky (cf. Egonsson 1990, Feldman 1997). (11) AXIcan be read in at least two different ways. On one reading pleasure is understood in a Sidgwickian sense such that when the person experiences that his desires have been satisfied he takes up some pro-attitude towards these experiences. To say that pleasure accompanies the fulfilment of intrinsic preferences, is therefore, in this sense, not saying that there is a phenomenological distinctive feeling that follows on the experience of having one's preferences satisfied. Rather, pleasure is understood as an experience towards which the person has some favourable attitude. This view is contested by the following: 
pleasure is a distinctive feeling that turns up whenever we experience that our preferences have become satisfied.

Whether or not it is the former or latter version we favour, it is hard to see why we would want to endorse $A X 1$. For one thing, given the plausible idea that pleasure accompany something else than preference-fulfilment, I do not see how one could support a value theory that singled out only one kind of pleasure as having intrinsic value. If it is being a state of pleasure that has value, then surely pleasure resulting from something else than preference-fulfilment should also be considered. But to agree to this is to leave (pure) preference-utilitarianism behind you. Still, the main reason, I suspect, why $A X 1$ or something akin to it has had few advocates (among modern utilitarians), is the fact that it leaves out from consideration a number of desires, the fulfilment of which in no way requires experiences on the part of the preferrer. Among a person's - past as well as present - preferences there will also typically be so-called "external preferences". (12) A preference of this kind is defined as a preference for a state of affairs other than the experiences of the preferrer. For instance, I want my daughters to be happy and I want this whether or not I will know that they are happy. Many of our preferences, I suspect, are of this kind. Moreover, they seem to be among the preferences that we are less ready to change and give up. On $A X 1$ such preferences have only value insofar they result in pleasure, and that seems to be a serious objection to becoming an advocate of $A X 1$.

In other words, $A X 1$ backs up the idea that we should never treat past preferences on a par with present (or future) ones. $A X 1$ even goes as far as saying that we should not give them any value at all. However, as we have seen it is imperative that we do not overlook the consequence of endorsing AXI: (13) To subscribe to this axiological position is a two-edged sword in the hands of a preference-utilitarian in that it excludes other kinds of preferences that he might find it reasonable to take into consideration.

\section{4.}

Our original question was whether preference-utilitarians should treat past preferences on a par with present ones. Let us next turn to the alternative (2), namely that we should always treat past-for-now preferences on a par with present preferences. This is the position we should expect to be endorsed by someone who subscribes to an unrestricted form of preference-utilitarianism:

$A X 2$ : intrinsic value is assigned to the circumstance that our intrinsic preferences are satisfied.

In comparison with the hedonistic version, its axiological horizon is considerably more extensive. On $A X 2$, preferences are to be satisfied whether or not the preferrer (or, for that matter, anyone else) receives any new experiences from the fulfilment. Thus, suppose my preference for the survival of the rhino is frustrated - at this very moment the last rhinos are killed. This would be bad even if I never found out that there were no more rhinos left in the world - even if it had no effect whatsoever on my conscious life.

Is it, then, $A X 2$ rather than $A X 1$ that we should endorse? Recall that we concluded that the hedonistic 
$A X I$, appears less convincing once we think of the many present preferences that do not require experiences at all to be satisfied. Endorsing $A X 2$ (and treating past-for-now preferences on a par with present ones) would therefore seem a sensible thing to do. But there is a price to be paid if we take this step. A number of different examples could be used to show this. Consider, for instance, a situation were someone, say Tom, is considering whether or not to sell a house that he has inherited from his parents. Having given the matter much attention he reaches the conclusion that he is actually indifferent to the question. However, he knows that his sister once strongly opposed the idea of selling the house of their childhood. What complicates the matter is that she has recently changed her mind. She now shows some interest in selling the house. It is clear to Tom that her original preference is stronger than her recent one.

Of course, the question of what Tom ought to do in this situation depends on many things (perhaps he considers not selling being a kind of 'paternalistic' way of threating his sister or perhaps he considers himself under some kind of obligation towards her that he does not think he has towards the 'past person). Notwithstanding, this should not prevent us from focusing on the very question: ought he to fulfill the past prefences at the cost of her now-for-now preference?

There is seemingly no obstacle other than, perhaps, an axiological one to having this kind of past preferences satisfied. Of course, we may have opinions about whether it is prudent of his sister to change his desires (and whether it is in her self-interest to satisfy a desire that will frustrate his actual one). Since we do in fact have now-for-future preferences, it might even seem a good practice to inculcate in people the idea of giving at least some weight to past preferences. This might be the case (or again, it might not). But whether or not, it is a question of what external value we should say that satisfying past preferences have. My problem is though a different one. Once we have put whatever other external reasons there are for satisfying past preferences aside (and there may be many such reasons for or againgst), utilitarianism ought to tell us something about the intrinsic (final) value of satisfying past preferences. In discussing this issue, I suspect that some, perhaps even most people would find it questionable to go along with what seems to be the preference-maximisation solution to this conflict.

What seems to be troubling at least some of us is that the fulfilment of a past-for-now preference can result in the experienced frustration of an actual preference. When the actual preference is weaker (either in isolation or together with other preferences), it seems counter-intuitive to make someone experience frustration in order to satisfy a preference from the past. (14)

The above example concerned a fairly authentic kind of case. However, sometimes a more fantastic situation may help us get clear about our intuitions. Thus, (to take a possibility at the very far end of a list of possibilities) suppose you would have to choose between which of two worlds that should go on existing. In the first one there exist beings that had those of their intrinsic preferences satisfied that had as their object pleasure (or, in some broad sense, experiences). The second world is one in which there are no beings at all - they have all died. However, in this world there are the objects of the past-for-now preferences of those who passed away. On $A X 2$, there is, then, the possibility that the latter world should be chosen, viz., when the past-for-now preferences outweigh the actual ones in terms of strength. 
But endorsing such a view does seem to me to be a counter-intuitive position to take.

Perhaps we reached a premature conclusion earlier? Maybe we should not have given up AX1? After all, for this hedonistic version of preferentialism the above problems would not arise in the first place, since only one kind of fulfilment will have intrinsic value, viz., the kind that is accompanied by pleasure. But again, the hedonistic version as we saw earlier, does seem far too narrow; it only gives value to external preferences as long as their fulfilment gives rise to pleasant experiences of the agent. And this, I suspect, many find it hard to accept. (15)

We are, then, seemingly faced with the dilemma of steering clear of the Scylla of $A X 1$ without being caught by the Charybdis of $A X 2$. The former leaves out too many important preferences, whereas the latter lets too many in at the possible cost of actual preferences. So what should preference-utilitarians do if they are not content with the hedonistic alternative but still find that treating past preferences on a par with actual preferences is somehow counter-intuitive? Time has come to consider the third attempt to answer our original question.

\section{5.}

The third answer to our original question was that we (3) should sometimes treat past-for-now preferences on a par with present preferences. This answer can also be specified in more than one way. There is the Exclusion version, (E3, for short), which says that we should sometimes treat past desires on a par with present ones and sometimes we should not ascribe any value at all to them, but we should never let them have more or less value that what their strength determines. Again, we may acknowledge the possibility of downgrading preferences and say that (W3) we should sometimes treat past desires on a par with present ones, and sometimes as having less value.

The version (E3) states in other words that sometimes the value of a past preference is determined purely in proportion to its strength. Such a position would be strengthened if we could among the past preferences single out preferences that due to their internal features were such that we could not reasonably want to treat them on a par with present preferences. But I doubt that there is such a group of preferences?

Now, Derek Parfit has drawn attention to a well-defined group of past desires, which might seem to serve us well here. Thus, he has convincingly argued that some past preferences need not worry us, since they are, what he calls, "implicitly conditional on their own persistence". This kind of preference will have the following general form: I prefer now that tomorrow $\mathrm{x}$ should be the case given that I then prefer $\mathrm{x}$ to be the case (alternatively, that I have not acquired a new preferences that is in conflict with my past one).

Now, Parfit's suggestion might seem to set out from something like (E3). But this would be a wrong conclusion to draw. The preferences which Parfit has in mind cannot be satisfied (or frustrated) unless the condition obtains. If the condition does not obtain, i.e., if the person has changed his preference for $\mathrm{x}$ when it is time to realize $\mathrm{x}$, it is reasonable to say that this kind of past preference have ceased to 
exist.

Some past-for-now preferences do seem to be of this kind. Parfit appears to think that it is notably those desires "whose fulfilment we believe would give us satisfaction, or whose non-fulfilment would make us distressed" that are of this kind. (16)

I have some quibbles with certain features of Parfit's account. (17) However those are topics for another work. The important thing here is that Parfit does seem to have a point that there are at least some such preferences. But the problem is that not all past preferences are of this kind. There are external preferences and there are non-external ones that are not implicitly conditional on their own persistence. The fact that we can exclude Parfit's kind of conditional preferences has not removed the burden that may have troubled some of us in the first place, namely how to deal with past preferences that can be fulfilled in the present. Parfit's suggestion indicates that there are less of these troublesome preferences. However, the fundamental axiological problem remains.

6.

Let us next consider the remaining option, the weight version (W3). It maintains that we should sometimes treat past desires on a par with present ones, and sometimes as having less value. Thus, this position shares an idea with what I earlier called (W1), viz. past-for-now preferences should never be treated on a par with present preferences because they should always be treated as having less value than what strength alone requires of us to give to them. (W3) as well as (W1) suggests that past preferences should be treated as having less value than what strength alone determines. (W3) adds that there are occasions when this is not true; (W1) denies this, maintaining as it does that past preferences without exception should never be treated on a par with present ones.

The problem with both these positions is, of course, how we are to justify this "downgrading" of past preferences. What do we have to add to $A X 1$ or $A X 2$ in order justify this measure? Recall that what is at issue here is not whether there are extrinsic features that may give us a reason to downgrade these past preferences. There might be, but that is besides the point. What we are interersted in here is the intrinsic value of prefence-satisfaction. Perhaps (W3) is the more promising one. After all, it suggests at least implicitly that we can divide past preferences into at least two groups, viz., those preferences that should be treated on a par with and those that should be given less value than present ones. However, I venture that there is no such obvious way of dividing past preferences. The proposal considered earlier, namely that we do not have to pay attention to what Parfit calls preferences that are implicitly conditional on their own persistence, does not solve the problem.

But could we not get around this problem by adding a clause to $A X 2$, which forbids past-for-now preferences to enter into "competition" with actual preferences? The fulfilment of past-for-now preferences would only have intrinsic value in certain circumstances, namely when they can be satisfied without frustration of actual preferences. But this approach will not do either - not, at any rate, if we want to retain a Moorean view on intrinsic value. On such a view an object's intrinsic value depends on its intrinsic nature rather than on extrinsic features such as being "in competition with present 
preferences". If something has intrinsic value in a situation, it has that intrinsic value in all situations. (18)

The idea that past preferences somehow should be equipped with a ballast or handicap is not that uncommon. (19) But as long as such a measure is not accompanied with a clear statement of how we should change $A X 1$ or $A X 2$, such attempts do seem unsatisfactory.

Actually there is an alternative that at least paves the way for a solution to the axiological issue here. However, choosing this alternative would in effect be tantamount to giving up a thesis central to preferentialism, viz., valuemonism. The theory I have in mind regards the satisfaction of different preferences as constituting different kinds of values (a preference for an object $\mathrm{x}$ would if satisfied consitute a preference-for- $x$ value, and satisfying a preference for an object y would consitute a preference-for-y value). On such a view there would not necessarily be anything strange in regarding the satisfaction of, say, a past preference-for- $x$ as having intrinsic value and not give a present preference-for-x any weight. Each particular preference would have to be judged on its own merits. On some occasions this might perhaps mean that being a past preference-for-x is sufficient to disqualify it as something the satisfaction of which constitutes value; other times it is being a preference-for-x that disqualifies it rather than being a past, present or future preference-for-x. But whatever the qualities of such particularistic valuepluralism are, it remains to be shown how such a view could be incorporated into a view as preference-utilitarianism. Until this is done there is a gauntlet which the preferenceutilitarian hopefully will take up, namely to provide us with some map that can help us steer clear of Scylla without running into Charybdis, taking us safe to a perhaps intermediary position between $A X 1$ and $A X 2$.

\section{7.}

I have considered three general and some particular positions that a preference-utilitarian reasonably would want to take with regard to past preferences. None of these positions seems entirely satisfactory. To deny any value to the fulfilment of past preference is, perhaps, what seems to accord best with our intuitions. A likely defence of this position is, as we saw, that the fulfilment of such past preferences will not give rise to any new experiences. Again, the problem with such a position is that it seems to exclude other kinds of preferences the fulfilment of which we appear to value highly (e.g. external preferences). Unfortunately, the second alternative did not seem much more convincing; treating pastfor-now preferences on a par with present ones has the consequence that we ought to satisfy past preferences at the expense of actual preferences, which appears absurd. Another possibility was to somehow downgrade past preferences. But as we have just seen, in the absence of an account of how to justify this downgrading, this alternative will not do either. The value pluralistic approach that I sketched above does not seem viable for a utilitarian. I am not aware of any other possible defence of these positions besides the ones considered. I conclude therefore, that preference-utilitarianism has a serious problem to deal with. (20) 


\section{Notes}

(1) W. Rabinowicz and J. Österberg, 'Value Based on Preferences', Philosophy and Economics, 1996, 12.

(2) For a discussion of some different positions with regard to past preferences see W. Rabinowicz, 'Actutilitarian prisoner's dilemmas', Theoria, 1989, vol. 1v, pp. 1-45. See also the recent dissertion (which I unfortunately have not had time to read) by Krister Bykvist (1998). Changing Preferences; A Study in Preferentialism. Uppsala University.

(3) See R. M. Hare (1981). Moral Thinking; Its Levels, Method and Point. Oxford: Clarendon Press.

(4) Hare (1981) discusses yet another group of preferences, viz. what he calls conditional preferences, i. e. preferences for hypothetical situations. However, such preferences, which should not be confused with hypothetical preferences, will not occupy us here. See e.g. Alan Gibbard, 'Hare's Analysis of 'Ought' and its implications', eds. D. Seanor and N. Fotion, Hare and Critics; Essays on Moral Thinking, Oxford: Clarendon Press, 1988.

(5) Past preferences raise another problem too, viz., whether we should take into consideration the duration of our preferences. However, in this paper I will side step this issue. For a discussion of this matter see Richard B. Brandt, A Theory of the Good and the Right: Oxford, Clarendon Press 1979, pp. 250.

(6) For a discussion of these matters, see David McNaughton and Eve Garrard 1996 (www.brown.edu/ Departments/Philosophy/bears/homepage.html). See also I. Persson, 'Benevolence, Identification, and Value', in Sten Lindström, Rysiek Sliwinski and Jan Österberg (eds.), Odds and Ends; Philosophical Essay Dedicated to Wlodek Rabinowicz on the Occasion of His Fiftieth Birthday. Uppsala Philosophical Studies 45, Uppsala University, 1996.

(7) Richard B. Brandt, Morality, Utilitarianism, And Rights: Cambridge UP, 1992, p. 171. Cf. Brandt 1979, p. 249.

(8) I use the term 'object' here in a wide sense that includes events.

(9) Actually, (la) can be understood in a different way. Suppose, as Rabinowicz (1989) has suggested, that we regard the utilitarian attitude as a "generalization of self-concern" (p. 25). Assume further that we are as a psychological fact future-oriented in our self-concern. In such a case utilitarianism will be future-oriented - in identifying myself with other subjects I will be concerned with them in a way that is similar to how I am concerned about myself. But even if our psychological set up was future-oriented (to what extent it is, seems to me, to still be an open matter), it is unclear which consequence it should have for our normative theory. Moreover, as Rabinowicz, later on admits, there is also the tricky question why we should not identify ourselves with a person in the past (see p. 31). 
(10) Actually, $A X I$ can be read as stating that the bearer of intrinsic value is the property of pleasure, or it can be taken to state that the bearer is rather the fact that someone is feeling pleasure. For a criticism of the former view, see Noah M. Lemos 1994, p. 22. In this paper I set aside the interesting question of what are the bearers of intrinsic value. On this matter, see Wlodek Rabinowicz and Toni RønnowRasmussen 'A Distinciton in Value: Intrinsic and For Its Own Sake' (forthcoming in the Proceeding of the Aritstotelian society).

(11) Dan Egonsson, Interests, Utilitarianism and Moral Standing. Lund UP, 1990. Fred Feldman, 'On the intrinsic Value of Pleasures'. Ethics, 107, pp. 448-466, 1997.

(12) See R. Dworkin, 'We Do Not Have a Right to Liberty', (ed.), R. Cunningham, Liberty and the Rule of Law: College Station: Texas University Press, 1979.

(13) This is, for instance, what Hare seems to be doing in 'Prudence and Past Preferences; Reply to Wlodzimierz Rabinowicz', Theoria, vol. LV art 3, 1989, pp. 152-158.

(14) It is less clear to me what we should say about a conflict between an external now-for-now preference and a past-for-now preference.

(15) Of course, over the years several attempts have been made to argue why it would be morally wrong to include such external preferences in a utilitarian weighing process. The better-known arguments are Dworkin (1979) and John C. Harsanyi, 'Problems with Act-preference-utilitarianism and with Malevolent Preferences', in (eds.), D. Seanor and N. Fotion (1988). Although these arguments reflect a widespread suspicion that there is something wrong in bringing such preferences onto the same stage as other preferences, the arguments have not been successful. Cf. H. L. A. Hart, 'Between Utility and Rights', Columbia Law Review, 79, (1979), pp. 828-846; R. M. Hare 'Comments on Harsanyi', in (eds.), D. Seanor and N. Fotion,1988.

(16) Derek Parfit, Reasons and Persons. Oxford: Clarendon press, 1984, p. 151.

(17) The uncertainty concerns actually two topics. First, there is the question what evidence can be forward for his claim that many of our preferences are of this kind. The nature of this kind of preferences seems to require that the propositional element in these preferences be of a highly complex nature. If this is right, is seems plausible to suspect that we do not in fact have many such preferences. Moreover, the idea that people do in fact change their preferences is no obvious evidence for this claim. What happens when we do change our preferences can be given an equally plausible explanation, namely that we retain the old desires; they are just weaker that the new ones we have acquired. Secondly, it is not obvious why Parfit focuses on preferences that give us satisfaction (or makes us distressed if unfulfilled).

(18) This point is not, and should not be taken as implying the falsity of what Moore called his principle 
of organic unities.

(19) Brandt, for instance, says in one place that there are cases where it seem plausible not to "ignore past desires altogether" (1992, p. 171), which does suggest that he wants to equip past preferences with a ballast. However, as far as I can judge he nowhere explains just what he means by this "altogether".

(20) For beneficial comments and discussions, I owe thanks to Dan Egonsson, Ingmar Persson, Wlodek Rabinowicz and J.J.C Smart. My work was supported by a generous grant from Crafoordska foundation, and I am thankful for this finacial help.

\section{Top of page}

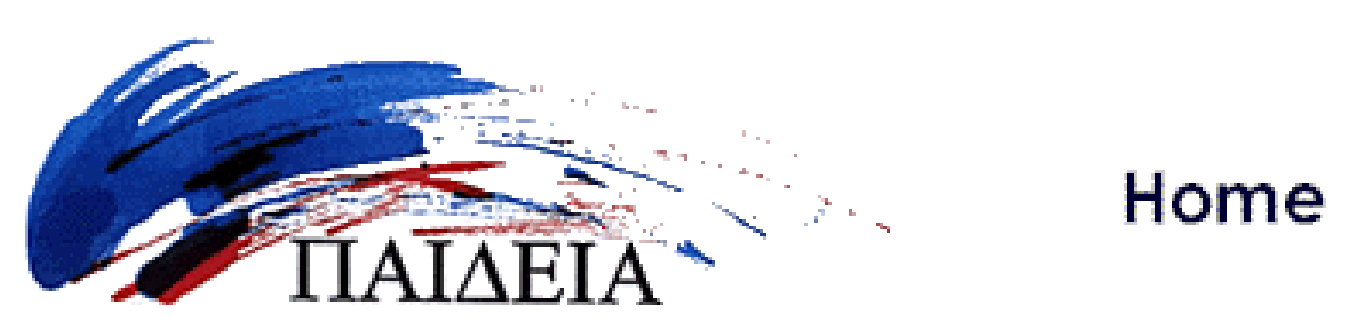

Paideia logo design by Janet L. Olson.

All Rights Reserved 